\title{
Microtubule Transport from the Cell Body into the Axons of Growing Neurons
}

\author{
Theresa Slaughter, Jun Wang, and Mark M. Black \\ Department of Anatomy and Cell Biology, Temple University School of Medicine, Philadelphia, Pennsylvania 19140
}

The present studies test the hypothesis that microtubules (MTs) are transported from the cell body into the axons of growing neurons. Dissociated sympathetic neurons were cultured using conditions that allow us to control the initiation of axon outgrowth. Neurons were injected with biotin-labeled tubulin (Bttub) and then stimulated to extend axons. The newly formed axons were then examined using immunofluorescence procedures for MTs with or without Bt-tub. Because the Bt-tub is fully assembly competent, all MTs that assemble after injection will contain Bt-tub. However, MTs that exist in the neuron at the time of injection and persist during the subsequent incubation will not contain Bt-tub. Because the neurons were injected before extending axons, MTs without Bt-tub are initially localized to the cell body. We specifically determined whether these
MTs appeared in the newly formed axon. Such a result can only be explained by the transport of these MTs from their initial location in the cell body into the axon. The newly formed axons of many neurons contained MTs both with and without Bt-tub. MTs without Bt-tub were detected all along the axon and in some neurons represented a substantial portion of the total polymer in the proximal and middle regions of the axon. These results show that MTs are transported from the cell body into growing axons and that this transport is robust, delivering MTs to all regions of the newly formed axon.

Key words: axon outgrowth; cultured sympathetic neurons; microtubules; microtubule transport; microinjection; biotinlabeled tubulin
Microtubules (MTs) have essential functions in the elaboration and maintenance of axonal structure. They serve as architectural elements, supporting the elongate shape of growing axons, and they are key components of the machinery that transports materials required for axon growth from their sites of synthesis in the cell body into the axon. Although it is clear that the mechanisms that generate and maintain the axonal MT array are fundamental to neuronal morphogenesis, the nature of these mechanisms is controversial.

Any model to explain the generation of the axonal MT array must account for its known properties. In this regard, several features of the MT array in axons are especially relevant. First, the number of MTs constituting the axonal MT array increases coordinately with axon growth (Stevens et al. 1988; Yu and Baas, 1994). Second, axonal MTs are shorter than the axon itself, and both the plus and minus ends of these MTs are free in the axoplasm (Chalfie and Thompson, 1979; Bray and Bunge, 1981; Tsukita and Ishikawa, 1981; Stevens et al., 1988; Yu and Baas, 1994). Third, axonal MTs have a uniform polarity orientation, with their plus ends pointing away from the cell body toward the axon tip (Heidemann et al., 1981; Burton and Paige, 1981). Finally, axonal MTs have a 13 protofilament substructure (Tilney et al., 1973; Burton et al., 1975).

The number of protofilaments that comprise MTs depends on the conditions of their assembly. Spontaneous assembly of tubulin or tubulin plus MT-associated proteins typically generates MTs

Received April 3, 1997; revised May 5, 1997; accepted May 9, 1997.

This work was supported by grants from the National Institutes of Health to M.M.B. We acknowledge Dr. Irina Tint for her help in establishing the culture system and also for many useful discussions throughout the course of this work.

Correspondence should be addressed to Dr. Mark M. Black, Department of Anatomy and Cell Biology, Temple University School of Medicine, 3400 North Broad Street, Philadelphia, PA 19140.

Copyright (C) 1997 Society for Neuroscience $0270-6474 / 97 / 175807-13 \$ 05.00 / 0$ with 14 or 15 protofilaments, not 13 protofilaments (Scheele et al., 1982; Evans et al., 1985). MTs with 13 protofilaments are, however, generated by discrete nucleating templates that constrain the assembly of tubulin into polymers specifically with 13 protofilaments (Scheele et al., 1982; Evans et al., 1985). This is the principle mode of assembly in cells, in which MTs are nucleated by the centrosome or other functionally analogous structures (Brinkley, 1985). In many and possibly all cells, the templating elements consist of $\gamma$-tubulin and other proteins organized into ring-like structures with 13 units (Moritz et al., 1995; Z heng et al., 1995). MT nucleation reflects the addition of tubulin onto these templates, thereby establishing the 13-protofilament substructure of MTs. Given these considerations, the fact that axonal MTs have 13 protofilaments indicates that they are generated by nucleating templates (Baas and Joshi, 1992).

Several observations suggest that axonal MTs are initially nucleated in the cell body, by the centrosome. First, studies examining MT assembly in axons have only observed assembly from the ends of existing MTs; no evidence has emerged of the nucleation of new MTs within the axon itself (Baas and Ahmad, 1992; $\mathrm{Li}$ and Black, 1996). Second, known components of MTnucleating structures such as $\gamma$-tubulin and pericentrin have not been detected in axons (Baas and Joshi, 1992) (J. Wang and M. Black, unpublished data). These components are, however, present in the soma, and in the case of $\gamma$-tubulin, specifically at the centrosome (Baas and Joshi, 1992). Furthermore, the centrosome is capable of nucleating large numbers of MTs (Yu et al., 1993; Wang et al., 1996). These observations raise the possibility that the MTs required for axonal growth are initially generated in the cell body. If this is correct, then models for generating the MT array of the axon must account for a somal origin of axonal MTs.

One possibility is that MTs nucleated in the cell body elongate into the axon to its tip. This possibility can, in principle, also 
account for the uniform polarity orientation of axonal MTs by postulating that MTs elongate specifically from their plus ends. In this way, MTs will grow from the cell body into the axon with their plus ends leading. If this is correct, then MTs should extend without interruption from the cell body to the axon tip. However, this is not the case for the vast majority of axonal MTs. Rather, both their plus and minus ends are located within the axon itself, and these ends do not seem to be associated with structural specializations that could serve as nucleating templates (Chalfie and Thompson, 1979; Bray and Bunge, 1981; Tsukita and Ishikawa, 1981; Stevens et al., 1988; Yu and Baas, 1994). Thus, the model of somal nucleation followed by elongation cannot account for the generation of the axonal MT array.

One model that can account for all of these features of the axonal MT array is the polymer transport model. This model was originally proposed to explain the axonal transport behavior of tubulin and other cytoskeletal proteins observed in whole animal studies and has been refined by more recent studies using tissue culture systems (for review, see Lasek, 1988; Black, 1994; Baas, 1997). This model proposes that MTs nucleated in the cell body by the centrosome are released and then transported into the axon by molecular motors. In this model, the centrosomal origin of axonal MTs accounts for their 13 protofilament substructure. In addition, the nucleation and release of large numbers of MTs from the centrosome (Yu et al., 1993) provides a steady supply of new MTs for the axon, thereby contributing to the expansion of the MT array that occurs during axon growth. The transport of MTs from the cell body into the axon also accounts for the observation that both ends of axonal MTs appear free in the axoplasm. Finally, the transport mechanisms can establish the polarity orientation of axonal MTs by conveying them specifically with their plus ends leading. In this regard, dynein is a logical candidate for the MT transport motor, because it translocates MTs with the appropriate polarity orientation, plus ends leading (Holzbaur and Vallee, 1994), and it is in the same transport compartment as MTs, namely slow axonal transport (Dillman et al., 1996).

Although the active transport of tubulin in axons is well documented (for review, see Black, 1994), the polymer transport model remains controversial because of the difficulties encountered in attempting to visualize MT transport in living neurons. On one hand, photobleaching and photoactivation studies in most cases have not revealed the transport of MTs or, for that matter, the movement of tubulin in any form (Lim et al., 1990; Okabe and Hirokawa, 1990; Sabry et al., 1995; Takeda et al., 1995). Given that tubulin is actively transported in some form, the interpretation of such negative data is not straightforward. On the other hand, more positive results have been obtained using alternative, more indirect strategies for studying MT transport. One series of studies used the drug vinblastine to suppress MT assembly as a means to examine the contributions of MT transport to the elaboration of the axonal MT array (Baas and Ahmad, 1993; Ahmad and Baas, 1995). These studies revealed a redistribution of MTs from the cell body into the axon in the absence of net assembly and even during net disassembly, and it was argued that this redistribution reflected MT transport. Although provocative, the possibility that assembly contributed to the observed redistribution of MTs could not be unequivocally dismissed because of the incomplete understanding of vinblastine action on live cells and specifically whether vinblastine can suppress MT assembly to the point that it is inconsequential. However, direct support for MT transport in axons has been provided subsequently by microinjecting biotin-labeled tubulin (Bt-tub) into cultured neurons with short axons, allowing the axons to grow longer, and then examining the newly formed part of the axon for MTs with or without Bt-tub (Yu et al., 1996). Although much of the MT polymer in the newly formed axon contained Bt-tub, some did not. Because the polymer without Bt-tub existed in the cell at the time of Bt-tub injection and did not turn over during the time course of the experiment, its presence in the part of the axon that grew after injection must reflect its transport there from more proximal sites.

In the present studies, we have used a similar strategy to test the hypothesis that MTs generated in the cell body are transported into the axon. We developed a culture system in which neurons can be triggered to initiate rapid axon growth. Neurons were injected with Bt-tub before initiating axon growth, and then they were stimulated to extend axons. We reasoned that the Bt-tub would mark all MTs formed after injection. However, MT polymer that existed at the time of injection and did not turn over would not contain Bt-tub. We determined whether this latter polymer, which is initially localized to the cell body, appears in the newly formed axon. Such a result would be indicative of the transport of this polymer from the cell body into the axon. Our results show that such transport occurs and that it is robust, delivering MTs from the cell body to all regions of the newly formed axon.

\section{MATERIALS AND METHODS}

Materials. Culture media were obtained from Life Technologies (Grand Island, NY). Supplements for culture media were obtained from Life Technologies or Sigma (St. Louis, MO), except for nerve growth factor, which was purified from mouse salivary glands according to the method of Mobley et al. (1976). Other reagents were obtained from Sigma unless otherwise indicated.

Cell culture. Dissociated cultures of rat sympathetic neurons were prepared using modifications of our previously published procedures (Brown et al., 1992; Black et al., 1996). These modifications permitted us to control when neurons initiate axon growth, and once initiated, axon growth proceeded relatively rapidly. Neurons were dissociated from superior cervical ganglia of 1- to 3-d-old rat pups using sequential treatments with collagenase and trypsin followed by trituration as described previously (Black and Kurdyla, 1983). The neurons were then plated in serum-free medium (Brown et al., 1992) onto glass coverslips pretreated with poly-L-lysine $(1 \mathrm{mg} / \mathrm{ml}$ in borate buffer $)$. The neurons attach to this substrate relatively rapidly, but they do not extend axons for $\sim 2 \mathrm{~d}$. During this period the cells remain round (see Fig. 1). To induce rapid axon outgrowth, the neurons are fed with medium containing $10 \%$ fetal calf serum and matrigel (Collaborative Biomedical Products), diluted 1:200-1:400 from the stock supplied by the company.

To determine the time course of initiation of axon outgrowth, sister cultures prepared as described above were fixed before or at varying times after addition of matrigel and serum. The cells were fixed for 10 min at room temperature with $0.3 \%$ glutaraldehyde in PEM buffer [containing (in mM) 80 PIPES, 5 EGTA, and $1 \mathrm{MgCl}_{2}, \mathrm{pH} 6.8$ (Black et al., 1996)]. The fixed cells were then viewed using phase-contrast optics and scored as having no processes, short processes (two cell body diameters or less in length), or axons (greater than two cell body diameters in length); two dishes were analyzed at each time point, and 250-350 cells were scored per dish.

Microinjection of biotinylated tubulin. Tubulin was purified from calf brains as described by Mitchison and Kirschner (1984) and then biotinylated using biotin- $N$-hydroxysuccinimide ester (Molecular Probes, Eugene, OR) following the protocol of Hyman et al. (1991). After the final assembly step, the Bt-tub-containing MTs were depolymerized in injection buffer [containing (in $\mathrm{mm}$ ) 50 potassium glutamate, 0.5 glutamic acid, and $\left.0.5 \mathrm{MgCl}_{2}, \mathrm{pH} 6.5\right]$, clarified by centrifugation, and then stored in aliquots. For storage, the Bt-tub was frozen in liquid $\mathrm{N}_{2}$ and then stored at $-80^{\circ} \mathrm{C}$. Immediately before use, the tubulin was thawed rapidly, diluted to $32 \mathrm{mg} / \mathrm{ml}$ [protein was determined using the BCA assay (Pierce, Rockford, IL) using bovine serum albumin as a standard], and then clarified by centrifugation at $200,000 \times g$ for $10 \mathrm{~min}$ in a Beckman Instruments (Palo Alto, CA) TL-100 ultracentrifuge to remove protein 
aggregates. The clarified Bt-tub was then pressure injected into cultured neurons using a Narishige (Tokyo, Japan) micromanipulator, an Eppendorf (Hamburg, Germany) injector, and micropipettes with a tip diameter $\leq 0.5 \mu \mathrm{m}$ (pipettes were prepared immediately before use with a Sutter Instruments CA P-97 pipette puller).

In all of the studies presented here, neurons were used on the day after plating, and only neurons without axons were injected. For some experiments, neurons were injected before addition of matrigel and serum to stimulate axon growth. In others, cultures were treated with matrigel and serum for 30-90 min, and then neurons without processes were selected for microinjection.

Cell extraction and fixation. Injected neurons were extracted and fixed 1-2 hr after injection to identify axonal MTs with or without Bt-tub. The extraction conditions were designed to remove unassembled tubulin, to stabilize existing MTs, and to cause sufficient loosening of the axonal MT array so that individual MTs can be visualized using immunofluorescence procedures (Brown et al., 1993). Specifically, cultures were rinsed once with PBS and once with PEM, and then extracted for 5 min with PEM containing $10 \mu \mathrm{M}$ taxol (a gift from the National Cancer Institute), protease inhibitors ( 0.2 trypsin inhibitory units/ml aprotinin and 10 $\mu \mathrm{g} / \mathrm{ml}$ each of leupeptin, chymostatin, and antipain), $0.5 \%$ Triton X-100, and $0.2 \mathrm{M} \mathrm{NaCl}$. The inclusion of $\mathrm{NaCl}$ in the extraction buffer causes a loosening of the axonal MT array so that individual MTs separate from each other for variable distances along their length and thus can be imaged using immunofluorescence procedures. The specific conditions used in the present studies are somewhat more gentle than previously described (Li and Black, 1996). These conditions caused less loosening of the axonal MT array compared with the previously described conditions but were better at preserving the overall morphology of the neurons.

After extraction, the cells were fixed with PEM containing $2 \%$ paraformaldehyde and $0.3 \%$ glutaraldehyde at room temperature for $10 \mathrm{~min}$, rinsed with PBS, treated with sodium borohydride $(10 \mathrm{mg} / \mathrm{ml}$ in PBS for $7 \mathrm{~min}$ ), incubated with $0.1 \mathrm{M}$ glycine in PBS for $20 \mathrm{~min}$, and rinsed with PBS again before incubation with blocking solution and then staining.

Immunofluorescence procedures. Neurons were double-stained using antibodies against biotin (Enzo Biochemicals, New York, NY) and $\beta$-tubulin (Amersham, Arlington Heights, IL) (Blose et al., 1984) to reveal MTs with Bt-tub and total MTs, respectively. Cells were incubated with blocking solution (PBS containing 10\% normal donkey serum) for 15 min just before incubation with primary antibodies (Abs) and again before incubation with secondary Abs. In addition, all Abs were diluted in blocking solution and then clarified before use by centrifugation at $200,000 \times g$ for $10 \mathrm{~min}$ in a Beckman TL-100 ultracentrifuge. Al secondary Abs were purchased from Jackson ImmunoResearch (West Grove, PA) (AffiniPure grade, preadsorbed for minimum crossreactivity). Incubations with primary $\mathrm{Abs}$ were for $45 \mathrm{~min}$ at $37^{\circ} \mathrm{C}$; incubations with secondary Abs were for $30 \mathrm{~min}$ at $37^{\circ} \mathrm{C}$, and after incubation with secondary Abs, cells were rinsed with PBS and then mounted in $50 \%(\mathrm{w} / \mathrm{v})$ glycerol/PBS containing $10 \mathrm{mg} / \mathrm{ml} n$-propyl gallate.

Two procedures were used to double stain MTs in injected neurons. In one, cells were incubated simultaneously with a mouse monoclonal $\mathrm{Ab}$ against $\beta$-tubulin, diluted 1:20, and a rabbit polyclonal $\mathrm{Ab}$ against biotin, diluted 1:100. After extensive rinsing with PBS and then reblocking, the cells were incubated with Lisamine-labeled goat anti-rabbit Ab, diluted 1:200, rinsed extensively with PBS, reblocked, and then incubated with a mixture of Lisamine-labeled rabbit anti-goat $\mathrm{Ab}$ and fluorescein (Fl)labeled donkey anti-mouse $\mathrm{Ab}$, diluted 1:200 and 1:50, respectively. With these procedures, MTs that contain Bt-tub stain for both $\beta$-tubulin and biotin, whereas MTs that do not contain Bt-tub only stain for $\beta$-tubulin.

In other experiments, we used the Ab blocking procedure described by Schulze and Kirschner (1987), as reported previously (Li and Black, 1996). For these analyses, the cells were incubated with the rabbit polyclonal $\mathrm{Ab}$ against biotin (diluted 1:100), rinsed well with PBS, and then incubated sequentially with four secondary Abs: first with Lisaminegoat anti-rabbit $\mathrm{Ab}$, diluted 1:200; second with Lisamine-rabbit anti-goat $\mathrm{Ab}$, diluted 1:200; third with unlabeled goat anti-rabbit Ab, diluted 1:100; and finally with unlabeled rabbit anti-goat $\mathrm{Ab}$, diluted 1:100. The cells were rinsed extensively and reblocked after each secondary Ab incubation. Then, the cells were incubated with the mouse monoclonal $\mathrm{Ab}$ against $\beta$-tubulin, diluted 1:20, rinsed extensively with PBS, and then incubated with a Fl-donkey anti-mouse $\mathrm{Ab}$, diluted 1:50. With these procedures, MTs that contain Bt-tub stain for biotin but not $\beta$-tubulin, whereas MTs without Bt-tub stain for $\beta$-tubulin but not biotin. In our hands these procedures produced variable results with regard to blocking $\beta$-tubulin staining of MTs with Bt-tub. For this reason, most experiments used the standard double-staining procedure described above.

Image acquisition. To examine the time course of axon growth induced by matrigel and serum, cells were observed by phase-contrast microscopy using a Zeiss (Thornwood, NY) Axiovert 35 inverted microscope and a $32 \times / 0.4$ numerical aperture (NA) achrostigmat objective together with a 0.3 NA condenser. Images of cells were captured with a Newvicon camera (Hamamatsu Photonic Systems, Bridgewater, NJ) interfaced to an Apple Quadra 950 computer using a pixel pipeline frame-grabber board (Perceptics Corp., Knoxville, TN), and the Oncor (Rockville, $\mathrm{MD})$ image processing and analysis software package. Axon lengths were determined on the basis of a one-pixel-wide line drawn down the center of the axon using programs written in our laboratory using the Oncor Imaging programming language.

Neurons were observed by epifluorescence microscopy using a Zeiss Axiovert 135 inverted microscope and a $100 \times / 1.3$ NA plan neofluar oil immersion objective (Zeiss), and images were obtained with a $\mathrm{CH} 250$ cooled CCD camera (Photometrics Ltd., Tucson, AZ) equipped with a Thompson 7883 CCD chip. The details of the imaging system have been described previously (Brown et al., 1992; Black et al., 1994; Li and Black, 1996). Images were acquired using the full usable area of the CCD chip, which measured $382 \times 576$ pixels, and stored in full 12 bit format on magneto-optical disks using Pinnacle optical disk drives (Pinnacle Micro Inc., Irvine, CA). Before capturing a series of images, an instantaneous readout of the bias voltage offset on the chip was saved and subsequently subtracted from each exposed image. Dark current (0.133 ADU/sec) was not significant for the exposure times used in these studies. The magnification of the CCD images was calibrated using a stage micrometer. For presentation, images were scaled to 8 bits, saved in TIFF format, and then imported into Adobe Photoshop to compose the figures; text and arrowheads were added using Adobe Illustrator. Colorized versions of the gray scale images obtained with the cooled CCD camera were prepared using functions within the Oncor Imaging software package.

\section{RESULTS}

Our goal in these experiments was to test the hypothesis that MTs are transported from the cell body into the axon of growing neurons. Neurons without axons were injected with relatively high amounts of Bt-tub and then stimulated to begin rapid axon outgrowth. At varying times thereafter, the neurons were extracted to remove unassembled tubulin and then double-stained using immunofluorescence procedures for Bt-tub and $\beta$-tubulin. The injected Bt-tub rapidly diffuses throughout the cell body and mixes with the endogenous tubulin. As a result, all microtubule polymer that assembles or turns over after injection should contain Bt-tub. By contrast, any polymer that existed at the time of injection and did not turn over during the subsequent incubation will not contain Bt-tub. This latter polymer could be identified by staining for $\beta$-tubulin but not for Bt-tub. We focused specifically on this latter, relatively long-lived polymer and determined whether it is transported from the cell body into the newly formed axon using the following reasoning. Because injection occurs before initiating axon growth, polymer without Bt-tub is initially located in the cell body. We determined whether, after extending axons, this relatively long-lived MT polymer appeared in the axon. Such a result, if obtained, can only be explained by the translocation of this MT polymer from its initial location in the cell body into the axon.

For these experiments to yield positive results, it is necessary not only that MTs undergo transport from the cell body into the axon, but also that enough MTs persist long enough to detect this transport. Several studies have shown that MTs in growing axons of cultured neurons are relatively dynamic. For example, in previous studies with rat sympathetic neurons, we showed that the majority of the MT polymer in the axon turns over with a $t_{1 / 2}$ of $\sim 1 \mathrm{hr}$ ( $\mathrm{Li}$ and Black, 1996), and similar results have been obtained in studies with other types of cultured neurons (Lim et al., 1990; Okabe and Hirokawa, 1990). It is not known whether this dynamic behavior also applies to MTs in the neuronal cell body, 

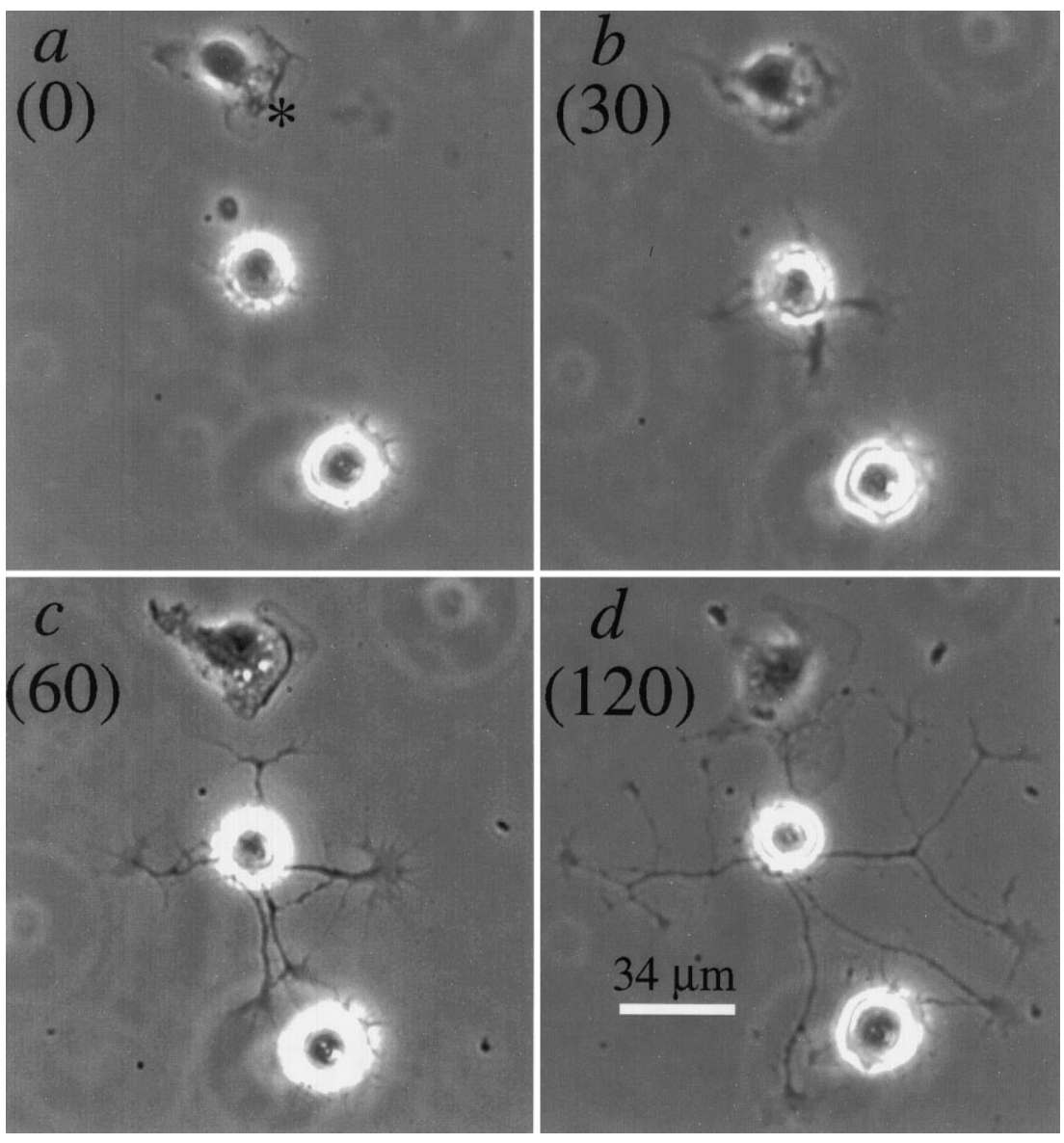

Figure 1. Stimulation of axon growth by matrigel and serum. Dissociated neurons were plated on poly-L-lysine, cultured overnight in serum-free medium, and then stimulated to extend axons by treatment with matrigel (1:400 dilution of stock) and $10 \%$ fetal calf serum as described in Materials and Methods. $a-d$, Phase images of a field containing two neurons and a non-neuronal cell $(*)$ at 0 , 30,60 , and $120 \mathrm{~min}$, respectively, after treatment with matrigel and serum. The upper neuron begins extending processes within $30 \mathrm{~min}$ of stimulation and by $2 \mathrm{hr}$ has extended five axons that elongate at $\sim 36 \mu \mathrm{m} / \mathrm{hr}$. The lower neuron initiates axon growth much later and has only relatively short process by $2 \mathrm{hr}$ of treatment.

although it seems unlikely that somal MTs will be less dynamic than axonal MTs. Thus, to optimize our chances of detecting the movement of these dynamic MTs from the cell body into the axon, we used culture procedures that allow us to control when neurons initiate axon growth, and that axon growth, once initiated, proceeds relatively rapidly. Below, we first describe the culture system. Then, we present the data testing the hypothesis that MTs are transported from the cell body into axons.

\section{The culture system}

Our standard culture system involves plating dissociated rat sympathetic neurons on a substrate consisting of poly-L-lysine and laminin (Brown et al., 1992). With these conditions, the neurons initiate axon growth after a variable delay that ranges over several hours. The relatively prolonged and asynchronous lag between plating and initiation of axon growth with these conditions was not suitable for our present purposes, so we modified the culture conditions to give better control over the initiation of axon growth. Dissociated rat sympathetic neurons were plated onto poly-L-lysine-coated coverslips in serum-free medium. The polyL-lysine promotes rapid attachment but is not permissive for axon growth for $\sim 2 \mathrm{~d}$. Thus, the neurons attach to the substrate and remain round. We were able to stimulate the neurons to extend axons at any time by adding matrix factors to the medium. Of the factors we tested, matrigel was the best in terms of stimulating the neurons to initiate axon growth relatively rapidly, and the time course of induction of axon growth could be increased substantially by including $10 \%$ fetal calf serum with the matrigel.

Figure 1 shows phase micrographs of two neurons plated on poly-L-lysine and then stimulated to extend axons with matrigel and serum. Before addition of matrigel and serum, both neurons are round and have no processes whatsoever. Both neurons extend axons after stimulation by matrigel and serum, but with very different time courses. One neuron initiates process formation within $30 \mathrm{~min}$ of stimulation, and the processes lengthen progressively with time; their growth rates average $36 \mu \mathrm{m} / \mathrm{hr}$. The other neuron responds more slowly, initiating process formation between 1 and $2 \mathrm{hr}$ after addition of matrigel and serum, and by 2 hr has relatively short processes. Quantitative analyses of the time course of axon formation induced by the addition of serum and varying amounts of matrigel are shown in Figure 2. For these analyses, neurons were scored as having no processes, short processes (two cell body diameters or less in length), or axons (greater than two cell body diameters in length). Before the addition of matrigel and serum, $\sim 80 \%$ of the cells had no processes whatsoever, whereas the remaining cells had short processes. When matrigel is used at a final dilution of 1:400 (Figs. 1, $2 A), \sim 40 \%$ of the neurons have short processes by $1 \mathrm{hr}$ after addition of matrigel, and by $2 \mathrm{hr}$, the majority have axons. With increasing time in matrigel, the proportion of neurons with axons increases, as does the length of the axons (Fig. 1). This time course can be accelerated somewhat by using matrigel at 1:200 (Fig. 2B), whereas an intermediate time course is obtained by starting the neurons in matrigel, diluted 1:400, and then increasing to 1:200 matrigel $1 \mathrm{hr}$ later (Fig. 2C).

More detailed microscopic inspection reveals that the initial morphological response of neurons to addition of matrigel and serum varies. Some cells seem to extend short processes (Fig. 1), whereas others extend broad lamellae (data not shown). With 

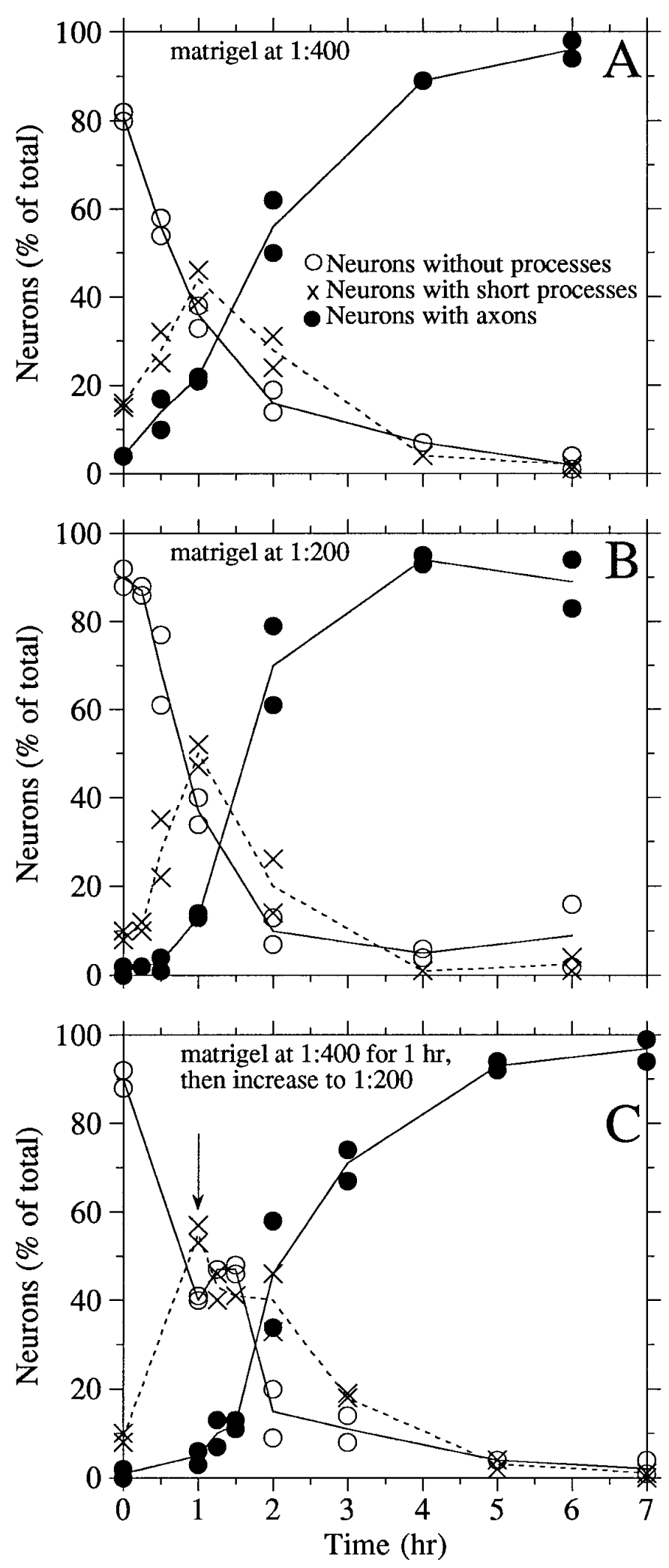

Figure 2. Quantitative analyses of the time course of initiation of axon growth after addition of matrigel and serum. Sister cultures of dissociated neurons plated on poly-L-lysine and cultured overnight in serum-free medium, were fixed before or at varying times after treatment with matrigel and $10 \%$ fetal calf serum as described in Materials and Methods. The fixed cells were viewed by phase-contrast optics and scored as having no processes, short processes (two cell body diameters or less in length), or axons (greater than two cell body diameters in length). Two dishes increasing time in matrigel and serum, the proportion of cells with lamellae declines, whereas that with processes increases. Once initiated, axon growth proceeds relatively rapidly. The rate of axon elongation was measured in cells monitored over a 2-4 hr period after addition of matrigel and serum. The rates of axon elongation spanned a broad range (range, $11-88 \mu \mathrm{m} / \mathrm{hr} ; n=27$ ), with an average of $42 \mu \mathrm{m} / \mathrm{hr}$.

\section{Transport of MTs from the cell body into the axon}

For most experiments, cells were grown in matrigel diluted 1:400 for $\sim 1 \mathrm{hr}$, and then round cells without any processes were identified and injected with a relatively high concentration (32 $\mathrm{mg} / \mathrm{ml}$ ) of Bt-tub. Pretreating with matrigel before injection reduced the time interval between injection of Bt-tub and initiation of axon growth. Injected cells were incubated an additional $1 \mathrm{hr}$ or more in medium containing matrigel diluted 1:200 to stimulate rapid axon growth, and then they were extracted using conditions that removed unassembled tubulin, including unassembled Bttub, and also caused modest loosening of the axonal MT array. This was necessary to visualize individual axonal MTs using immunofluorescence procedures (see Materials and Methods). Extracted cells were then fixed and doubled-stained using antibodies against $\beta$-tubulin and biotin to reveal all MTs and MTs with Bt-tub, respectively. The results described below are based on analyses of injected cells that extended axons during the 1-2 hr period after injection.

Figures 3 and 4 show a cell extracted $1 \mathrm{hr}$ after injection of Bt-tub. The cell had no processes at the time of injection. Thus, between injection and extraction, the neuron extended a single axon that bifurcated into two branches. The longest branch is $\sim 88 \mu \mathrm{m}$ long (measured from the cell body-axon transition to the axon tip), corresponding to an average growth rate of $\sim 88$ $\mu \mathrm{m} / \mathrm{hr}$. Figure 3 shows the staining for Bt-tub and $\beta$-tubulin using a multicolor overlay approach in which MTs that stain for both Bt-tub and $\beta$-tubulin appear orange, whereas MTs that stain for $\beta$-tubulin but not Bt-tub appear green. Many MTs with Bt-tub can be seen throughout the axon (Figs. 3, 4), from its beginning to its tip. In addition, many MTs that stain for $\beta$-tubulin but not Bt-tub can also be seen (Figs. 3, 4). These latter MTs are present throughout the axon; they are especially abundant in the proximal and middle portions of the axon, and they are also present distally near the growth cones as well.

In these experiments, Bt-tub is used as a probe to tag MTs that assemble after its injection. Thus, MTs that do not contain Bt-tub must have existed in the cell at the time of injection and also persisted throughout the duration of the experiment. These relatively long-lived MTs were initially present in the cell body, because the neuron was injected before initiating axon outgrowth. Thus, the presence of MTs without Bt-tub in the newly formed axon must reflect their transport there from the cell body during the incubation subsequent to injection. In the cell depicted in Figures 3 and 4, this transport is robust, delivering many MTs to all regions of the newly formed axon. Indeed, the majority of the MTs in the middle portion of the longer axon branch seem to

were analyzed at each time point, and 250-350 cells were evaluated per dish. The graphs show the results for each dish, with the lines connecting the average of the two dishes at each time point. $A, B$, Time course of axon initiation after stimulation by matrigel at a dilution of 1:400 or 1:200, respectively. $C$, Time course resulting from matrigel treatment at 1:400 for the first hour followed by 1:200 for the remaining time. 


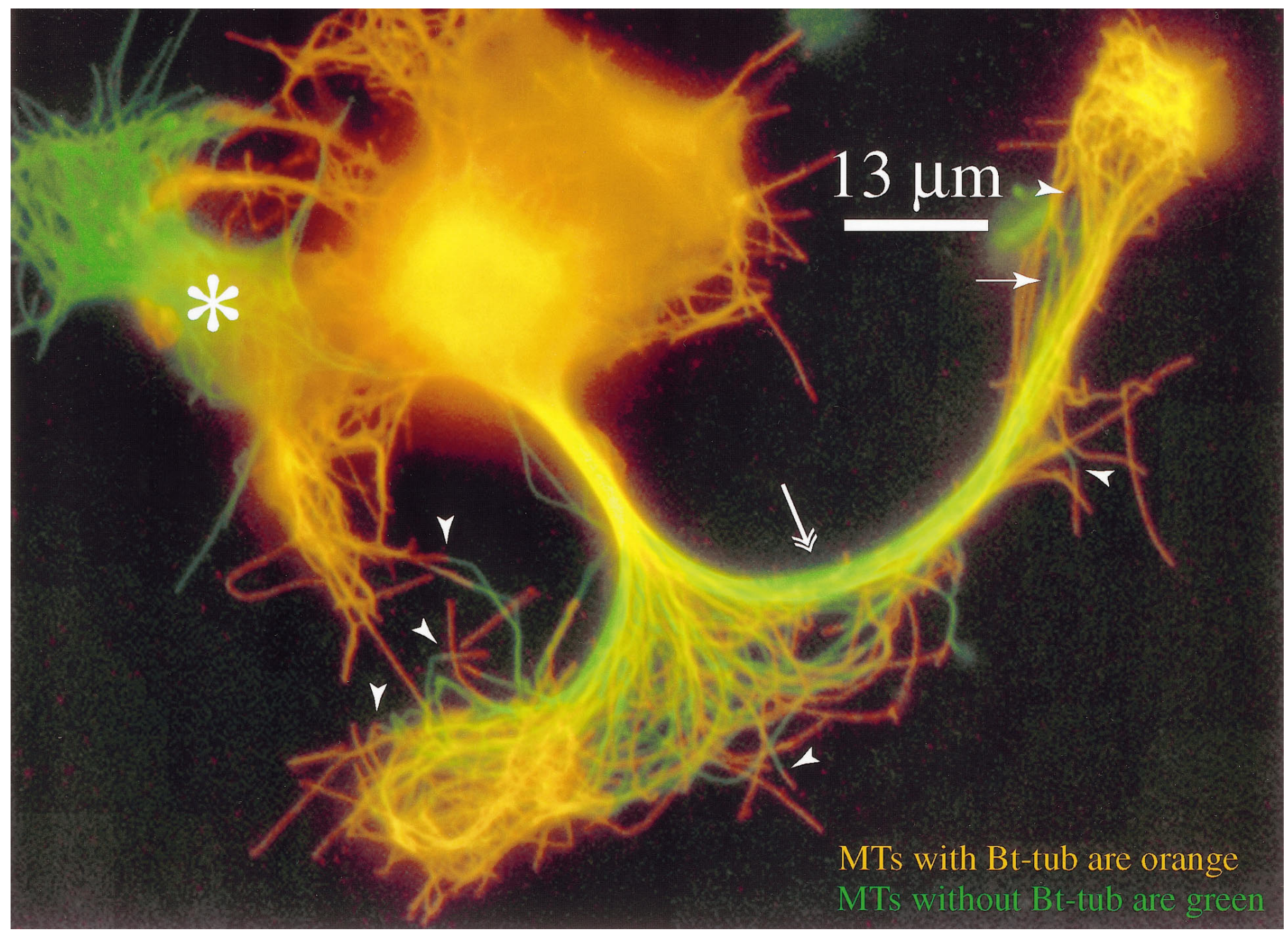

Figure 3. Multicolor overlay image depicting the localization of MTs with or without Bt-tub. To generate this image, the gray scale images depicting $\beta$-tubulin and Bt-tubulin staining were overlayed, and the result is depicted with color so that MTs that stain for both Bt-tub and $\beta$-tub appear orange, whereas MTs that stain for $\beta$-tubulin but not Bt-tub appear green. Many MT profiles that stain for both $\beta$-tubulin and Bt-tub are present throughout the axon. MT profiles that stain for $\beta$-tubulin but not Bt-tub are also present. As indicated in Results, these correspond to MTs transported from the cell body into the axon. These transported MTs are present throughout the newly formed axon, although they are especially abundant in its proximal and middle regions. Several MT profiles were also observed that stained for $\beta$-tub over their entire length but stained for Bt-tub over only a part of their length (see Fig. 4 for more details). The arrowheads identify the transition along some of these MTs from regions that do not stain for Bt-tub to regions that stain for Bt-tub. The arrow identifies one of several MT profiles in the distal part of the axon that does not stain for Bt-tub. The double-headed arrow indicates a region in the middle part of the axon in which MTs that stain for $\beta$-tubulin but not Bt-tub are especially abundant and seem to constitute a majority of the total polymer present. The asterisk identifies a non-neuronal cell that was not injected with Bt-tub; note that all of its MTs appear green.

have been transported from the cell body (see Figs. 3, 4, axonal region identified with a double-headed arrow). We estimated the transport rate by measuring the distance from the beginning of the axon to the distal tip of MTs without Bt-tub and then dividing this distance by the time interval between microinjection and processing ( $1 \mathrm{hr}$ for this cell). Only a limited number of MTs without Bt-tub were detected in which their distal tips were apparent, and based on these we calculated a broad range of rates $(27-72 \mu \mathrm{m} / \mathrm{hr} ; n=13)$, with an average transport rate of 44 $\mu \mathrm{m} / \mathrm{hr}$. These calculations have not taken into account the lag period between injection and the initiation of axon growth, and they also assume that transport proceeds uniformly for the entire incubation period. Thus, the calculated values represent minimal estimates of MT transport rate.

Many of the transported MTs have incorporated Bt-tub at their distal ends relative to the cell body (see Figs. 3, 4, arrowheads). We assume that this assembly occurs specifically at the plus end, because axonal MTs are uniformly plus end distal in orientation (Burton and Paige, 1981; Heidemann et al., 1981; Baas et al., 1988). This assembly could have occurred in the cell body before the MTs were translocated into the axon and/or locally in the axon. The available data do not allow us to distinguish between these possibilities. Nonetheless, we assume that at least some of this assembly occurred locally in the axon, because axonal MTs are assembly competent at their plus ends (Okabe and Hirokawa, 1988; Baas and Ahmad, 1992; Li and Black, 1996). This in turn raises the possibility that MTs can add (or lose) subunits as they are translocated in the axon.

In addition to the presence of MTs without Bt-tub, polymer with Bt-tub is also present in the newly formed axon, and it seems especially enriched at its tip. The presence of Bt-tub in this polymer indicates that it formed after the injection of Bt-tub. As discussed above, some of this polymer formed by assembly of Bt-tub onto the ends of transported MTs. Also, given the robust 


\section{Biotinylated MTs}

\section{Total MTs}
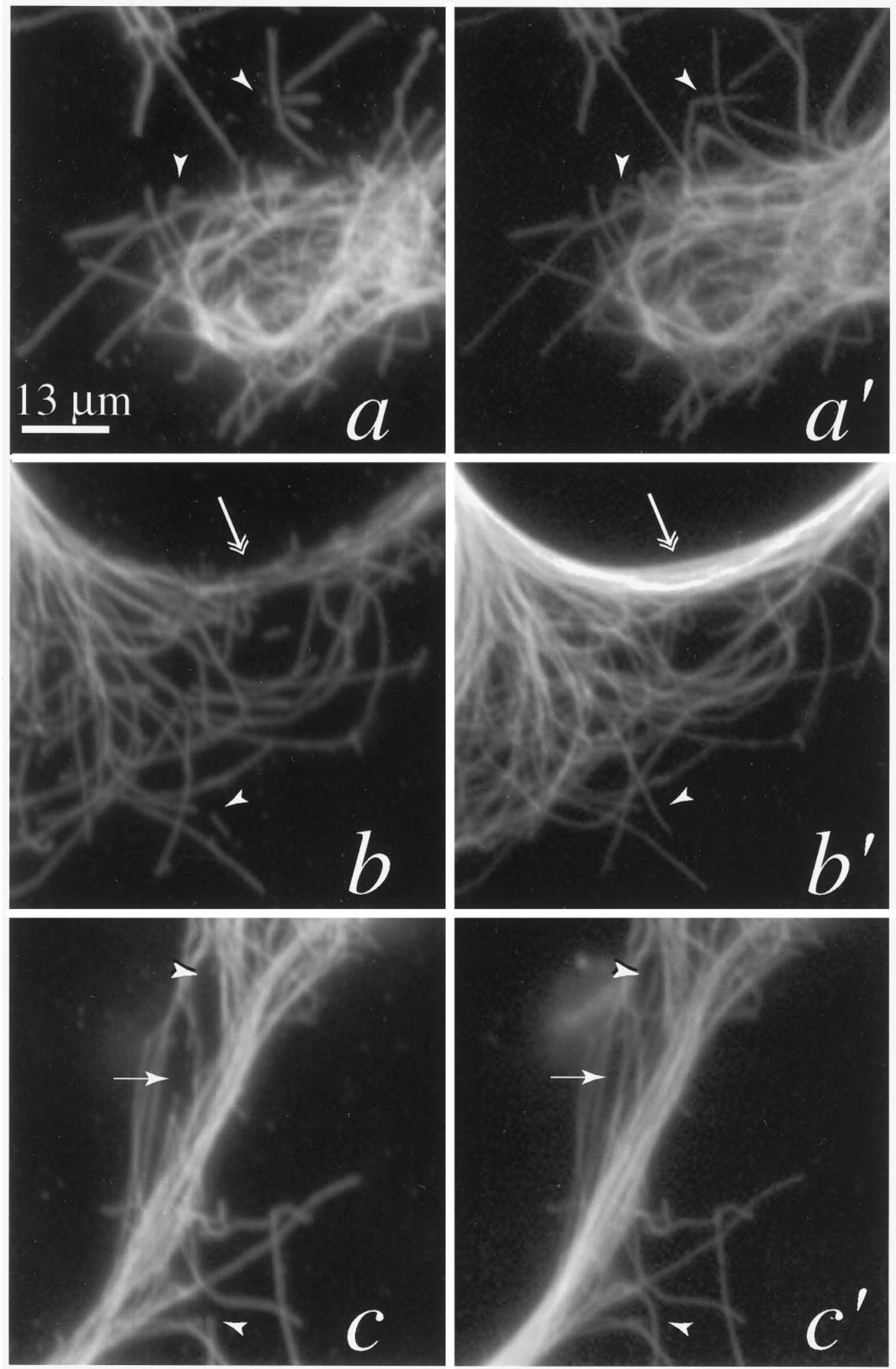

Figure 4. High-magnification views depicting the localization of MTs with or without Bt-tub. Shown are zoomed views of portions of the cell depicted in Figure 3. $a-c$, Images of MTs stained for Bt-tub. $a^{\prime}-c^{\prime}$, Images of MT staining for $\beta$-tubulin (total MTs). $a$, $a^{\prime}$, Region near the tip of the shorter axon branch. $b, b^{\prime}$, Region between the two axon branches. $c, c^{\prime}$, Region near the tip of the longer axon branch. The arrowheads and arrows identify the same MT profiles highlighted in Figure 3. 
nature of MT transport in this cell, it seems reasonable that new MTs containing Bt-tub were nucleated in the cell body, presumably at the centrosome (Yu et al., 1993), and then transported into the axon. The extent to which new, Bt-tub-containing MTs are generated locally in the axon by spontaneous or nucleated assembly is not known. However, it has been argued that such events occur rarely if at all, and that all assembly in axons occurs by elongation from MT ends (Baas and Heidemann, 1986; Baas and Black, 1990; Baas and Ahmad, 1992). If this is correct, then the appearance of Bt-tub-containing polymer in these axons reflects a combination of only two mechanisms, transport from assembly sites in the cell body and local assembly onto transported MTs.

Figures 5 and 6 show additional examples of cells injected with Bt-tub before the initiation of axon growth. After injection, these neurons extended axons at rates ranging from $39 \mu \mathrm{m} / \mathrm{hr}$ (Fig. $6 b$ ) to $77 \mu \mathrm{m} / \mathrm{hr}$ (Fig. 5). In all of these examples, MTs without Bt-tub are present in the newly formed axon, indicating the transport of MTs from the cell body into the axons of these cells. The specific cells shown depict the range of observations obtained in these experiments. Transported MTs, that is, MTs without Bt-tub, were most abundant in the proximal and middle parts of the axon; they were also detected more distally, but usually in much lower numbers relative to more proximal sites. Also, most cells contained one or more examples of transported MTs that incorporated Bt-tub onto their distal end. The number of transported MTs observed in any individual cell was quite variable. In some cases, as exemplified by the cell shown in Figures 3 and 4, a relatively large number of MTs without Bt-tub were apparent, whereas in others, comparatively few (Fig. 6b) or no MTs (data not shown) without Bt-tub were seen. Some of this variability reflects the normal dynamics of MT turnover in these axons. Although we did not measure MT turnover directly, our ability to detect polymer without Bt-tub in cells declined with increasing time between injection and fixation, and in cells examined $\geq 2 \mathrm{hr}$ after injection, few (Fig. 6b) or no (data not shown) MTs without Bt-tub were detected. Thus, the time course of MT turnover in these neurons is such that relatively little polymer persists for $>2$ $\mathrm{hr}$. In the present studies, neurons typically were fixed between 1 and $2 \mathrm{hr}$ after injection (for example, the neurons depicted in Figs. 3, 5, $6 a, b$ were fixed $1,1.25,1.5$, and $2 \mathrm{hr}$, respectively, after injection). Although the range in these times is relatively small, it is great enough relative to the time course of MT turnover to contribute to the variation in the amount of polymer without Bt-tub observed in these cells. A second factor that contributes to the variability observed in the number of MT profiles without Bt-tub concerns the methods used to visualize individual MTs by immunofluorescence procedures. Ordinarily, the spacing between axonal MTs is too small to resolve the signal of one MT from its neighbors using immunofluorescence procedures. To overcome this, the neurons were extracted before fixation using conditions that cause individual MTs to separate from each other for variable distances along their lengths (see Materials and Methods). However, as can be seen in Figures 3, 5, and 6, the degree of loosening is variable from one cell to another (also see Brown et al., 1993). Because of this variability, we suspect that the amount of MT polymer without Bt-tub seen in these axons is less than the true amount present.

Finally, an important issue in considering these data is the actual portion of polymer at any particular site in the axon that arrived there by polymer transport versus local assembly. Unfortunately the data obtained in these experiments do not readily lend themselves to quantitative analyses. However, the multicolor overlay approach strongly suggests that transported microtubules can constitute a substantial portion of the total polymer in proximal and middle regions of the axon. Specifically, transported microtubules without biotin-labeled tubulin are depicted with green, whereas microtubules with biotin-tubulin (which may or may not be transported) are depicted with orange. In the cells shown in Figures 3 and 5 especially, but also in the cell shown in Figure $6 a$, the proximal and middle portions of the axon appear yellow to green. This result could not occur if the transported microtubules constituted only a small portion of the total polymer in these regions. Thus, even though we cannot measure how much of the polymer in the proximal and middle portions of these axons arrived by transport from the cell body, we can conclude that the proportion is not minor but must be substantial.

\section{DISCUSSION}

The present experiments have tested the hypothesis that MTs are transported from the cell body into the axon of growing neurons. Cells were injected with Bt-tub before initiating axon growth to tag all MT polymer formed after injection. We then stimulated the cells to extend axons and examined the newly formed axons specifically for MT polymer without Bt-tub. MTs without Bt-tub were observed throughout the newly formed axons from their proximal regions to near their tips, and in some axons (see Figs. 3-5), they represented a substantial portion of the total polymer in the axon, especially in its proximal and middle regions. The absence of Bt-tub from this polymer indicates that it existed in the cell at the time of injection and also persisted throughout the subsequent incubation. Furthermore, because the cells had not initiated axon growth at the time of injection, this polymer was initially localized to the cell body. The finding that this polymer is present in the newly formed axon at later times can only be explained by its transport there from its initial location in the cell body.

Although slow axonal transport of tubulin is well documented (for review, see Lasek, 1988), disagreement exists regarding the mechanisms of this movement. The hypothesis that the transport machinery conveys cytoskeletal polymers, and specifically that tubulin is transported in the form of MTs, was originally proposed to explain the detailed behavior of cytoskeletal proteins as they moved down the axon toward the axon tip of mature neurons in vivo (Black, 1994; Baas, 1997). The present data fully support this hypothesis and add to a growing body of literature documenting the transport of cytoskeletal polymers in axons. Most notably in this regard, Yu et al. (1996), using experimental strategies similar to those used here, showed that some of the MT polymer in the distal part of growing axons is transported there from more proximal sites in the neuron. Also, Terasaki et al. (1995) microinjected fluorescently labeled MTs stabilized with taxol into the squid giant axon and observed a time-dependent redistribution of the polymers consistent with anterograde slow axonal transport. Finally, Reinsch et al. (1991) and Okabe and Hirokawa (1992), using photoactivation approaches, revealed the anterograde movement of MTs in cultured Xenopus motor neurons. The conclusion that MTs are transported in axons is inescapable.

Despite these data, it is frequently argued that MTs are stationary, and that tubulin moves either as subunits or oligomers (Sabry et al., 1995; Takeda et al., 1995; Funakoshi et al., 1996; Miller and Joshi, 1996). These proposals are not well supported by the existing data. For example, many photobleaching and photoactivation studies have not revealed the transport of MTs (Lim et al., 1990; Okabe and Hirokawa, 1990, 1992; Sabry et al., 


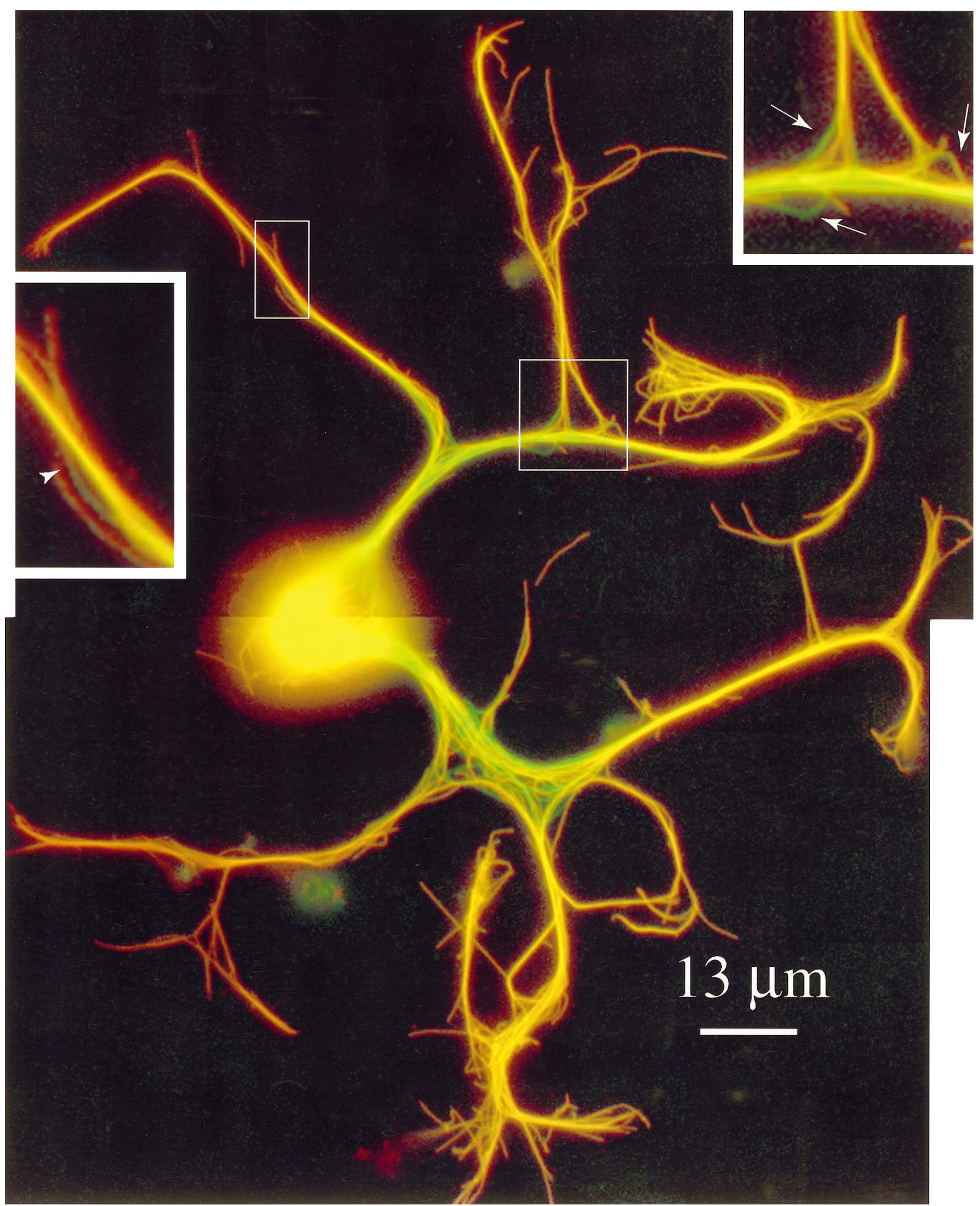

Figure 5. Multicolor overlay depicting MTs with or without Bt-tub in newly formed axons. The neuron was incubated for $1.25 \mathrm{hr}$ after injection with Bt-tub and then extracted, fixed, and double-stained as described in the legend to Figure 3 (also see Materials and Methods). Axons of this cell grew at an average rate of $\sim 75 \mu \mathrm{m} / \mathrm{hr}$. MTs containing Bt-tub stain for both $\beta$-tubulin and biotin and appear orange, whereas MTs without Bt-tub only stain for $\beta$-tubulin and appear green. The extraction procedure resulted in relatively little loosening of the axonal MT array. Nonetheless, MT profiles without Bt-tub are clearly apparent in the axons of this cell. Insets, Zoomed views of regions depicting details of MT staining for Bt-tub and $\beta$-tubulin. Inset to the left, MT profile that stains for Bt-tub only over its more distal extent; the arrowhead identifies the transition between the region without Bt-tub and the region with Bt-tub. Inset to the right, Region containing several MT profiles without Bt-tub, some of which are highlighted with arrows. 

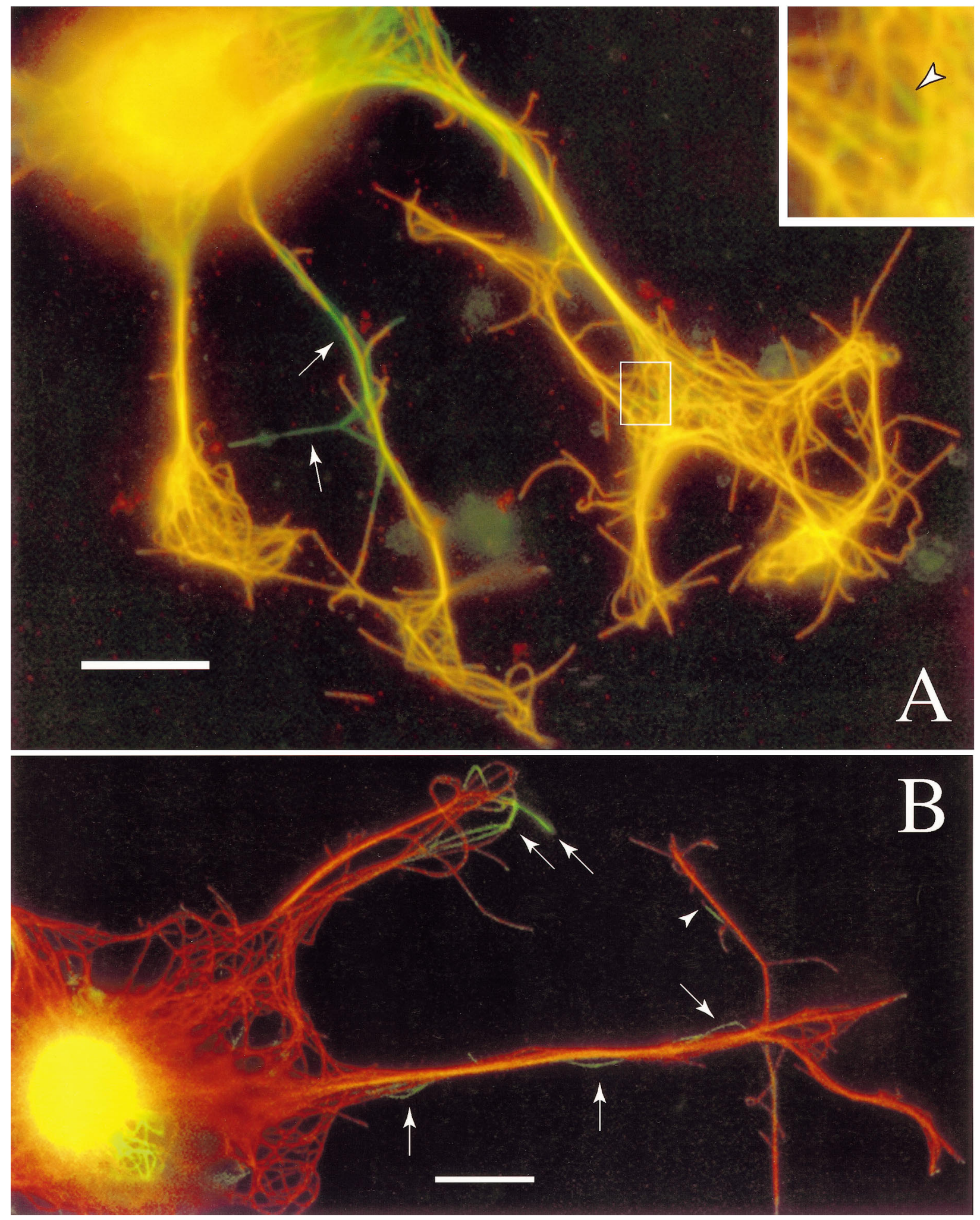

Figure 6. Multicolor overlay depicting MTs with or without Bt-tub in newly formed axons. $a$, Neuron incubated with medium containing matrigel (1:400) and serum for $\sim 1 \mathrm{hr}$ before injection. After injection, matrigel was increased to 1:200, the cell was incubated for an additional $1.5 \mathrm{hr}$, and then it was double-stained for Bt-tub and $\beta$-tubulin using standard procedures. Axons of this cell grew at an average rate of $\sim 42 \mu \mathrm{m} / \mathrm{hr}$. MTs containing Bt-tub stain for both $\beta$-tubulin and biotin and appear orange, whereas MTs without Bt-tub only stain for $\beta$-tubulin and appear green. $b$, Neuron that was injected before adding matrigel and serum. Immediately after injection, matrigel and serum were added to 1:400 and 10\%, respectively, and the cell was incubated for $\sim 2 \mathrm{hr}$. The longer axon of this cell grew at an average rate of $\sim 39 \mu \mathrm{m} / \mathrm{hr}$. The cell was stained using the antibody-blocking procedure (see Materials and Methods). MTs that contain Bt-tub stain for biotin but not $\beta$-tubulin and appear red, whereas MTs without Bt-tub only stain for $\beta$-tubulin and appear green. In both examples, MT profiles without Bt-tub are apparent throughout the axons (arrows). Inset in $a$, Zoomed view of a region in the base of the growth cone in which an MT profile without Bt-tub is clearly apparent (arrowhead). Scale bars, $13 \mu \mathrm{m}$. 
1995; Takeda et al., 1995). However, these studies have also failed to reveal the movement of tubulin in any form. Given that tubulin is actively transported in some form, interpretation of these negative data is problematic. More recently, Funakoshi et al., (1996) used immunoelectron microscopy after photoactivation in an attempt to study the transport of tubulin. They detected no marked tubulin in MTs outside of the photoactivated region during a $1 \mathrm{hr}$ period after photoactivation, but they did detect marked tubulin outside of this region. The authors argued that this latter tubulin corresponded to tubulin subunits or oligomers, and that this represented the transport form of tubulin. In our opinion, the data do not justify this interpretation. First, to test for MT transport, caged fluorescein tubulin injected into neurons was photoactivated at a discrete site along the axon. At varying times thereafter, the neurons were extracted to remove unassembled tubulin, fixed, and then stained to reveal photoactivated tubulin in MTs using anti-fluorescein antibodies and second antibodies conjugated to $5 \mathrm{~nm}$ gold particles. In these analyses, the highest density of MT labeling should be observed in the photoactivated region at relatively short times after photoactivation. The actual density observed in this region is relatively low (Funakoshi et al., 1996, their Fig. 2). Detecting movement of these MTs would require that they retain sufficient photoactivated tubulin after incubation to stain above background. The likelihood of satisfying this criterion is uncertain given the initial low labeling observed in the photoactivated region together with the relatively rapid rate of MT turnover that occurs in these axons (Okabe and Hirokawa, 1990, 1992). Thus, it is unclear whether the experiments could reveal MT movements if they occurred.

In their other experiments, Funakoshi et al. (1996) provided evidence consistent with tubulin transport in axons. Specifically, caged fluorescein tubulin injected into neurons was photoactivated at a discrete site along the axon. The neurons were then fixed without preextraction and stained with an antibody against fluorescein and second antibodies conjugated to $1.4 \mathrm{~nm}$ gold particles. Silver enhancing was used to detect these gold particles, because it greatly increases the signal attributable to the gold particles. With these procedures, staining was observed in the photoactivated region and at sites distal to it. This distal labeling may reflect photoactivated tubulin that was actively transported from the photoactivation site. Because the cells were not extracted before fixation, the distal staining could reflect photoactivated tubulin in unassembled form or in MTs. Funakoshi et al. (1996) did not examine the form of this material directly. Instead, they attributed it entirely to tubulin subunits or oligomers solely on the basis of their inability to detect MT labeling in the experiments on extracted neurons described above. Because these experiments do not effectively address this issue (see above), the interpretation that the distal labeling observed in the analyses of unextracted neurons represents exclusively tubulin subunits or oligomers is not well supported.

Miller and Joshi (1996) have also argued against MT transport on the basis of two observations. In one, fluorescently labeled MTs chemically stabilized with ethylene glycol-bis(succinic acid $N$-hydroxysuccinimide ester) did not move when injected into neurons but instead aggregated in the cell body. The significance of these negative data is unclear, especially given the positive results obtained by Terasaki et al. (1995), who observed anterograde axonal transport of fluorescent MTs stabilized with taxol. In their other experiments, neurons grown in the presence of 1 nM vinblastine overnight were injected with fluorescently labeled tubulin. At varying times thereafter the neurons were extracted to remove unassembled tubulin before visualizing fluorescent tubulin in MTs. Using this procedure, a mass of labeled MTs was seen initially in the proximal part of the axon, and then over $\sim 30 \mathrm{~min}$ it appeared more distally. The most straightforward interpretation of these data are that the fluorescent tubulin assembles into MTs in the cell body, after which some of these MTs are transported down the axon. However, the authors propose a different explanation in which tubulin subunits move down the axon as a wave, assembling and then disassembling coordinately from the ends of stationary MTs. If this is correct, then the unassembled fluorescent tubulin should exhibit a wave-like distribution in the axons of injected cells, and the position of the wave should exhibit the same time-dependent change as observed for the labeled MTs. Miller and Joshi (1996) did not test this prediction, because all of their analyses were performed after extraction to remove unassembled tubulin. However, other studies have shown that tubulin injected into neurons rapidly diffuses down the axon, exhibiting a proximal to distal decline that can be modeled as an exponentially declining function (Okabe and Hirokawa, 1988; Li and Black, 1996). These studies did not reveal a wave-like distribution of tubulin as postulated by Miller and Joshi (1996). Thus, their model requires unassembled tubulin to behave in a manner that is contradicted by the available data on its diff usive mobility in axons (also see Baas, 1997).

We have argued that the studies proposing that MTs are stationary in axons and that tubulin is transported in a form other than MTs do not effectively address the issues at hand. By contrast, several recent observations, including those presented here, have provided clear and unambiguous support for the hypothesis that MTs are actively transported in axons. In the introductory remarks, we discussed how MT transport can, in and of itself, establish many features of the MT array in axons. The demonstration of MT transport in axons provides essential support for this perspective, as does the steadily increasing number of reports that show that motor proteins move and organize MTs in the cytoplasm of a variety of cell types (Barton and Goldstein, 1996; Gaglio et al., 1996; Heald et al., 1996; Hyman and Karsenti, 1996). These latter observations further indicate that the MT transport hypothesis does not invoke novel mechanisms but instead proposes adaptations of basic cell biological mechanisms that operate in many cell types. An important goal for the future is to define the molecular mechanisms and physiological regulation of MT transport in neurons.

One of the more dramatic results presented here concerns the extent to which the MT transport mechanisms deliver MTs to the growing axon. Although precise quantitative determinations are not possible on the basis of the available data, in some cells, a substantial portion of the MT polymer present in the proximal and middle parts of the newly formed axon as well as some of the polymer present more distally, near the growth cone, is delivered from the cell body by MT transport. Thus, MT transport clearly has a substantial role in generating the MT array in the axons examined in the present studies.

Is MT transport equally robust in other growing neurons? We can only speculate as to the answer to this question. Our view is that axonal transport of MTs occurs in all neurons. This derives from several considerations, including the facts that tubulin transport is a constitutive process in neurons and that all studies that have succeeded in detecting this movement at a cellular level indicate that tubulin is axonally transported in the form of MTs (Reinsch et al., 1991; Okabe and Hirokawa, 1992; Terasaki et al., 1995; Yu et al., 1996) (present studies). We further propose that 
the negative data regarding MT transport obtained in many photobleaching and photoactivation studies reflect a failure to detect this motility rather than its absence. In this regard, photobleaching and photoactivation require that a substantial portion of the marked polymer move en masse to detect its movement. Such coherent movement occurs in Xenopus motor neurons in culture (Reinsch et al., 1991; Okabe and Hirokawa, 1992), and this presumably is one of the reasons why MT transport was successfully revealed in these neurons using photoactivation and photobleaching approaches. However, in other systems, MTs do not seem to move in this way but, rather, seem to move asynchronously and intermittently (Yu et al., 1996). Such behavior would be difficult to detect with photobleaching or photoactivation approaches, because most of the marked polymer would remain in the initial marked zone during the relatively short time course of these experiments. This problem is further exacerbated by the rapid exchange of subunits between monomer and polymer pools that occurs in growing axons (Lim et al., 1990; Okabe and Hirokawa, 1990, 1992; Li and Black, 1996), which would have the effect of diminishing the signal of the marked polymer independent of its movement. On the basis of these considerations, we suggest that the nature of MT movements in many axons together with the limitations inherent in the photobleaching and photoactivation methods have combined to frustrate many attempts to reveal this transport with these methods.

We have not determined whether photoactivation or photobleaching approaches would reveal MT transport in the neuronal preparation used in the present studies. However, given the robust nature of MT translocation in some of these neurons, it is difficult to imagine that these approaches would not reveal this movement. If this is correct, then the inability of these approaches to reveal MT transport in other types of neurons suggests that MT transport in these neurons is less robust than in the neurons used in the present studies. One notable difference among these neurons is the rate of axon growth. In the present studies, axon elongation is quite rapid, averaging $\sim 42 \mu \mathrm{m} / \mathrm{hr}$. This is considerably faster than the rates attained by many other neurons in culture, including those used in the studies that failed to detect MT transport using photoactivation or photobleaching approaches. One exception to this is Xenopus motor neurons, which extend axons at rates faster than those reported here, and, as indicated above, axonal transport of MTs has been revealed in these neurons using photobleaching and photoactivation procedures. These considerations raise the possibility that specific features of MT transport correlate with axon growth rate, and furthermore, that these features determine at least in part the relative ease with which MT transport can be detected. For example, the speed and coherence of MT transport may be greater in rapidly growing axons compared with slowly growing axons, and both of these features of MT transport will facilitate its detection by photobleaching and photoactivation methods. Implicit in this view is that the properties of MT transport vary from one type of neuron to another, and that this may reflect regulatory mechanisms that adjust parameters of MT transport in accordance with the physiological state of the neuron.

Although the discussion thus far has focused on MT transport in the delivery of MTs required for axon growth, this is not meant to diminish the importance of assembly-disassembly mechanisms in the generation of the MT array in growing axons. Indeed, many studies have documented relatively high levels of MT assembly and disassembly in growing axons (Lim et al., 1990; Okabe and Hirokawa, 1990; Li and Black, 1996; Yu et al., 1996) and that MT assembly-disassembly dynamics influence aspects of growth cone motility involved in axon elongation (Tanaka et al., 1995). We and others have argued that MT transport and assembly-disassembly dynamics occur concurrently, with axonal MTs gaining or losing subunits as they are translocated down the axon (Black, 1994; Baas and Yu, 1996). A precedent exists for MTs undergoing length changes during active translocation in vitro (Belmont et al., 1990; Hyman and Karsenti, 1996). Although direct demonstration of this in intact axons has yet to be achieved, we observed examples of MTs that had undergone both translocation from the cell body into the axon and addition of Bt-tub onto their distal ends. These observations suggest that most or all transported MTs are dynamically active at their the distal end, adding and losing subunits while in transit toward the axon tip. We envision a scenario in which both assembly-disassembly dynamics and polymer transport mechanisms operate on individual MTs throughout the axon to determine their length and location. In this way, both MT transport and assembly-disassembly dynamics combine to establish the architecture of the MT array of the axon and thereby contribute directly to the elaboration of axonal morphology.

\section{REFERENCES}

Ahmad FJ, Baas PW (1995) Microtubules released from the neuronal centrosome are transported into the axon. J Cell Sci 108:2761-2769.

Baas PW (1997) Microtubules and axonal growth. Curr Opin Cell Biol 9:29-36

Baas PW, Ahmad FJ (1992) The plus ends of stable microtubules are the exclusive nucleating structures for microtubules in the axon. J Cell Biol 116:1231-1241.

Baas PW, Ahmad FJ (1993) The transport properties of axonal microtubules establish their polarity orientation. J Cell Biol 120:1427-1437.

Baas PW, Black MM (1990) Individual microtubules in the axon consist of domains that differ in both composition and stability. J Cell Biol 111:495-509.

Baas PW, Heidemann SR (1986) Microtubule reassembly from nucleating fragments during the regrowth of amputated neurites. J Cell Biol 103:917-927.

Baas PW, Joshi HC (1992) $\gamma$-tubulin distribution in the neuron: implications for the origins of neuritic microtubules. J Cell Biol 119:171-178.

Baas PW, Yu W (1996) A composite model for establishing the microtubule arrays of the neuron. Mol Neurobiol 12:145-161.

Baas PW, Deitch JS, Black MM, Banker GA (1988) Polarity orientation of microtubules in hippocampal neurons: uniformity in the axon and nonuniformity in the dendrite. Proc Natl Acad Sci USA 85:8335-8339.

Barton NR, Goldstein LSB (1996) Going mobile: microtubule motors and chromosome segregation. Proc Natl Acad Sci USA 93:1735-1742.

Belmont LD, Hyman AA, Sawin KE, Mitchison TJ (1990) Real-time visualization of cell cycle-dependent changes in microtubule dynamics in cytoplasmic extracts. Cell 62:579-589.

Black MM (1994) Microtubule assembly and transport cooperate to generate the microtubule array of the axon. Prog Brain Res 102:61-77.

Black MM, Kurdyla JT (1983) Microtubule-associated proteins of neurons. J Cell Biol 97:1020-1028.

Black MM, Slaughter T, Fischer I (1994) Microtubule-associated protein $1 \mathrm{~b}$ (MAP1b) is concentrated in the distal region of growing axons. J Neurosci 14:857-870.

Black MM, Slaughter T, Moshiach S, Obrocka M, Fischer I (1996) Tau is enriched on dynamic microtubules in the distal region of growing axons. J Neurosci 16:3601-3619.

Blose SH, Meltzer DI, Feramisco JR (1984) $10 \mathrm{~nm}$ filaments are induced to collapse in living cells microinjected with monoclonal and polyclonal antibodies against tubulin. J Cell Biol 98:847-858.

Bray D, Bunge MB (1981) Serial analysis of microtubules of cultured rat sensory neurons. J Neurocytol 10:589-605.

Brinkley BR (1985) Microtubule organizing centers. Annu Rev Cell Biol 1:145-172.

Brown A, Slaughter T, Black MM (1992) Newly assembled microtubules are concentrated in the proximal and distal regions of growing axons. J Cell Biol 119:867-882. 
Brown A, Li Y, Slaughter T, Black MM (1993) Composite microtubules of the axon: quantitative analyses of tyrosinated and acetylated tubulin along individual microtubules. J Cell Sci 104:339-352.

Burton PR, Paige JL (1981) Polarity of axoplasmic microtubules in the olfactory nerve of the frog. Proc Natl Acad Sci USA 78:3269-3273.

Burton PR, Hinkley RE, Pierson GB (1975) Tannic acid stained microtubules with 12,13 , and 15 protofilaments. J Cell Biol 65:27-233.

Chalfie M, Thompson JN (1979) Organization of neuronal microtubules in the nematode Caenorhabditis elegans. J Cell Biol 82:278-289.

Dillman III JF, Dabney LP, Pfister KK (1996) Cytoplasmic dynein is associated with slow axonal transport. Proc Natl Acad Sci USA 93:141-144.

Evans L, Mitchison T, Kirschner M (1985) Influence of the centrosome on the structure of nucleated microtubules. J Cell Biol 100:1185-1191.

Funakoshi T, Takeda S, Hirokawa N (1996) Active transport of photoactivated tubulin molecules in growing axons revealed by new electron microscopic analyses. J Cell Biol 133:1347-1354.

Gaglio T, Saredi A, Bingham JB, Hasbani MJ, Gill SR, Schroer TA, Compton DA (1996) Opposing motor activities are required for the organization of the mammalian mitotic spindle pole. J Cell Biol 135:399-414.

Heald R, Tournebize RR, Blank T, Sandaltzopoulos R, Becker P, Hyman A, Karsenti E (1996) Self organization of microtubules into bipolar spindles around artificial chromosomes in Xenopus extracts. Nature 382:420-425.

Heidemann SR, Landers JM, Hamborg MA (1981) Polarity orientation of axonal microtubules. J Cell Biol 91:661-665.

Holzbaur ELF, Vallee RB (1994) Dyneins: molecular structure and cellular function. Annu Rev Cell Biol 10:339-372.

Hyman AA, Karsenti E (1996) Morphogeneitic properties of microtubules and mitotic spindle assembly. Cell 84:401-410.

Hyman A, Drechsel D, Kellogg D, Salser S, Sawin K, Steffen P, Wordeman L, Mitchison T (1991) Preparations of modified tubulins. Methods Enzymol 196:478-485.

Lasek RJ (1988) Studying the intrinsic determinants of neuronal form and function. In: Intrinsic determinants of neuronal form and function (Lasek RJ, Black MM, eds), pp 1-58. New York: Liss.

Li Y, Black MM (1996) Microtubule assembly and turnover in growing axons. J Neurosci 16:531-544.

Lim S-S, Edson KJ, Letourneau PC, Borisy GG (1990) A test of microtubule translocation during neurite elongation. J Cell Biol 111:123-130.

Miller KW, Joshi HC (1996) Tubulin transport in neurons. J Cell Biol 133:1355-1366.

Mitchison T, Kirschner MW (1984) Microtubule assembly nucleated by isolated centrosomes. Nature 312:232-237.

Mobley WC, Shenker A, Shooter EM (1976) Characterization and isolation of proteolytically modified nerve growth factor. Biochemistry 15:5543-5551.
Moritz M, Braunfeld MB, Sedat JW, Alberts B, Agard DA (1995) Microtubule nucleation by $\gamma$-tubulin-containing rings in the centrosome. Nature 378:638-640.

Okabe S, Hirokawa N (1988) Microtubule dynamics in nerve cells: analysis using microinjection of biotinylated tubulin into PC12 cells. J Cell Biol 107:651-664.

Okabe S, Hirokawa N (1990) Turnover of fluorescently labeled tubulin and actin in the axon. Nature 343:479-482.

Okabe S, Hirokawa N (1992) Differential behavior of photoactivated microtubules in growing axons of mouse and frog neurons. J Cell Biol 117:105-120.

Reinsch SS, Mitchison TJ, Kirschner M (1991) Microtubule polymer assembly and transport during axonal elongation. J Cell Biol 115:365-379.

Sabry J, O'Connor TP, Kirschner MW (1995) Axonal transport of tubulin in Ti1 pioneer neurons in situ. Neuron 14:1247-1256.

Scheele RB, Bergen LF, Borisy GG (1982) Control of structural fidelity of microtubules by initiation sites. J Mol Biol 154:485-500.

Schulze E, Kirschner M (1987) Dynamic and stable microtubule populations in cells. J Cell Biol 104:277-290.

Stevens JK, Trogadis J, Jacobs JR (1988) Development and control of axial neruite form: a serial electron microscopic analysis. In: Intrinsic determinants of neuronal form and function (Lasek RJ, Black MM, eds), pp 115-146. New York: Liss.

Takeda S, Funakoshi T, Hirokawa N (1995) Tubulin dynamics in neuronal axons of living zebrafish embryos. Neuron 14:1257-1264.

Tanaka E, Ho T, Kirschner MW (1995) The role of microtubule dynamics in growth cone motility and axonal growth. J Cell Biol 128:127-138.

Terasaki M, Schmidek A, Galbraith JA, Gallant PE, Reese TS (1995) Transport of cytoskeletal elements in the squid giant axon. Proc Natl Acad Sci USA 92:11500-11503.

Tilney LG, Bryan J, Bush DJ, Fujiwara K, Mooseker MS, Murphy DB, Snyder DH (1973) Microtubules: evidence for 13 protofilaments. J Cell Biol 20:267-275.

Tsukita S, Ishikawa H (1981) The cytoskeleton in myelinated axons: serial section study. Biomed Res 2:424-437.

Wang J, Yu W, Baas PW, Black MM (1996) Microtubule assembly in growing dendrites. J Neurosci 16:6065-6078.

Yu W, Baas PW (1994) Changes in microtubule number and length during axon differentiation. J Neurosci 4:2818-2829.

Yu W, Centonze VE, Ahmad FJ, Baas PW (1993) Microtubule nucleation and release from the neuronal centrosome. J Cell Biol 122:349-359.

Yu W, Schwei MJ, Baas PW (1996) Microtubule transport and assembly during axon growth. J Cell Biol 133:151-157.

Zheng Y, Wong ML, Alberts B, Mitchison T (1995) Nucleation of microtubule assembly by a $\gamma$-tubulin-containing ring complex. Nature 378:578-583. 